\title{
Haemodynamic Comparisons of Atrial Pacing and Exercise in Patients with Angina Pectoris
}

\author{
RAPHAEL BALCON*, JUDITH HOY, WILLIAM MALLOY, AND EDGAR SOWTON \\ From The Institute of Cardiology and the National Heart Hospital, London W.I
}

Though exercise is the most physiological test for angina pectoris, it has several disadvantages. The most important are that, it is difficult to achieve a steady state, comparable haemodynamic parameters are not readily reproducible during repeated periods of exercise (Burkart, Barold, and Sowton, 1967), it cannot be used effectively in patients with poor exercise tolerance, and angina pectoris cannot be terminated rapidly.

The use of an atrial pacing technique to induce angina pectoris or electrocardiographic changes under safe controlled conditions in patients with coronary artery disease has recently been reported by our own group (Sowton et al., 1967) and others (Lau et al., 1967a, b; Friesinger, Conti, and Pitt, 1967).

So far 60 patients have been studied by this technique, and in this paper our results are reported on comparing atrial pacing with an effort test in a group of 16 patients with ischaemic heart disease who were being assessed for possible revascularization surgery. This comparison was made to determine how far the results of the atrial pacing test could be used as part of the clinical evaluation, and the procedures were carefully explained to all patients in advance.

In a previous communication we showed that angina occurred at the same tension-time index on repeated pacing runs (Sowton et al., 1967). This index was chosen because it bears some relation to myocardial oxygen consumption in animal experiments (Sarnoff et al., 1958), and it has been used again in the present report. If the concept of a threshold for anginal pain is valid, the maximal myocardial oxygen uptake per minute should be the same no matter how the pain is produced. It seems possible, therefore, that the tension-time index may

Received September 5, 1968.

* Reprint requests to: R. Balcon, Institute of Cardiology, London, W.1. also be approximately the same at the onset of pain, providing factors such as ventricular volume do not change appreciably.

\section{SUBJECTS AND METHODS}

Sixteen male patients, aged 34 to 59 years (mean 51), were studied. All had a clinical history of angina pectoris and electrocardiographic changes indicating left ventricular ischaemia. Patients with heart failure, hypertension, other forms of heart disease, and pulmonary disease were excluded. They were studied in the supine position and were not fasted or premedicated.

The following procedure was used.

A Zucker bipolar electrode catheter was passed via an antecubital vein to the right atrium near its junction with the superior vena cava. It was then adjusted slightly until a position was found where stable atrial pacing could be maintained requiring no more than 3 volts from an external battery-powered pacemaker unit.

A No. 8 twin lumen catheter was passed via another antecubital vein and under fluoroscopic control into the pulmonary artery so that the distal opening was in the pulmonary wedge position and the proximal opening in a pulmonary artery.

A plastic tube (OD $1.6 \mathrm{~mm}$., ID $1.1 \mathrm{~mm}$.) was inserted into a brachial artery using the Seldinger technique and the tip passed to the aortic arch.

Pressures were measured using Consolidated Electrodynamics strain gauge transducers (Type 4-326-L212) and recorded on a Sanborn-964 four-channel direct writer. The mean pressures were obtained by electrical integration. The zero level for pressure reference was taken at the mid-chest. Cardiac output was determined by the dye-dilution technique, $5 \mathrm{mg}$. indocyanine green being injected into the pulmonary artery, and arterial blood was withdrawn by a Kipp and Zonen constant rate pump through a Gilford densitometer feeding a Honeywell recorder.

The following haemodynamic parameters were measured: heart rate (from the electrocardiogram), cardiac output, pulmonary artery, aortic, pulmonary "wedge", and right atrial pressures. Tension-time 168 
TABLE I

DATA FROM 14 PATIENTS AT POINT OF PAIN INDUCED BY PACING AND EXERCISE

\begin{tabular}{|c|c|c|c|c|c|c|c|c|c|c|c|c|c|c|}
\hline \multirow[b]{2}{*}{$\begin{array}{c}\text { Patient, age } \\
\text { (yr.), and sex }\end{array}$} & \multicolumn{7}{|c|}{ Pacing } & \multicolumn{7}{|c|}{ Exercise } \\
\hline & $\begin{array}{c}\text { Heart } \\
\text { rate } \\
\text { (beats/ } \\
\text { min.) }\end{array}$ & 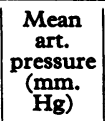 & $\begin{array}{c}\text { Syst. } \\
\text { ejection } \\
\text { time } \\
(\mathrm{sec} .)\end{array}$ & $\begin{array}{l}\text { Ten- } \\
\text { sion- } \\
\text { time } \\
\text { index }\end{array}$ & $\left|\begin{array}{c}\text { Cardiac } \\
\text { output } \\
(1 . / \\
\text { min.) }\end{array}\right|$ & $\begin{array}{c}\text { Stroke } \\
\text { vol. } \\
\text { (ml.) }\end{array}$ & \begin{tabular}{|c|} 
Syst. \\
ejection \\
rate \\
(ml./ \\
sec.)
\end{tabular} & $\begin{array}{c}\text { Heart } \\
\text { rate } \\
\text { (beats/ } \\
\text { min.) }\end{array}$ & 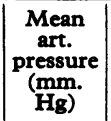 & $\begin{array}{l}\text { Ejec- } \\
\text { tion } \\
\text { time } \\
(\mathrm{sec} .)\end{array}$ & $\begin{array}{l}\text { Ten- } \\
\text { sion- } \\
\text { time } \\
\text { index }\end{array}$ & $\left|\begin{array}{c}\text { Cardiac } \\
\text { output } \\
(1 . / \\
\text { min.) }\end{array}\right|$ & $\begin{array}{c}\text { Stroke } \\
\text { vol. } \\
\text { (ml.) }\end{array}$ & 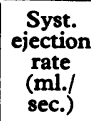 \\
\hline $\begin{array}{lll}\text { G.H. } & 45 & \mathrm{~F} \\
\text { H.T. } & 49 & \mathrm{M} \\
\text { M.H. } & 38 & M \\
\text { T.L. } & 47 & M \\
\text { A.P. } & 51 & M \\
\text { P.D. } & 41 & M \\
\text { C.M. } & 56 & M \\
\text { A.C. } & 57 & M \\
\text { T.W. } & 58 & M \\
\text { G.L. } 59 & M \\
\text { E.H. } & 72 & M \\
\text { N.S. } & 61 & M \\
\text { A.H. } & 34 & M \\
\text { D.H. } & 45 & M\end{array}$ & $\begin{array}{l}125 \\
110 \\
130 \\
115 \\
110 \\
140 \\
135 \\
114 \\
135 \\
99 \\
118 \\
134 \\
132 \\
130\end{array}$ & $\begin{array}{r}103 \\
85 \\
78 \\
98 \\
109 \\
128 \\
98 \\
103 \\
130 \\
83 \\
130 \\
90 \\
85 \\
107\end{array}$ & $\begin{array}{l}0.25 \\
0.26 \\
0.26 \\
0.25 \\
0.24 \\
0.21 \\
0.22 \\
0.25 \\
0.24 \\
0.27 \\
0.27 \\
0.21 \\
0.22 \\
0.26\end{array}$ & $\begin{array}{l}3565 \\
2790 \\
2680 \\
3034 \\
3155 \\
3985 \\
3025 \\
3430 \\
4640 \\
2590 \\
4900 \\
3070 \\
2990 \\
4275\end{array}$ & $\begin{array}{r}4 \cdot 3 \\
5 \cdot 4 \\
6 \cdot 1 \\
7 \cdot 4 \\
\frac{8 \cdot 4}{8 \cdot 4} \\
3 \cdot 7 \\
4.9 \\
= \\
7 \cdot 0 \\
7 \cdot 6 \\
12 \cdot 7\end{array}$ & $\begin{array}{l}34 \cdot 1 \\
49 \cdot 1 \\
46 \cdot 9 \\
64 \cdot 3 \\
58 \cdot 0 \\
65 \cdot 0 \\
32 \cdot 9 \\
36 \cdot 0 \\
= \\
56 \cdot 0 \\
57 \cdot 6 \\
97 \cdot 7\end{array}$ & $\begin{array}{l}136 \cdot 4 \\
189 \cdot 0 \\
180 \cdot 4 \\
257 \cdot 0 \\
27 \overline{0} \cdot 3 \\
295 \cdot 5 \\
131.6 \\
155 \cdot 0 \\
\overline{-} \\
266 \cdot 7 \\
262 \cdot 0 \\
375 \cdot 5\end{array}$ & $\begin{array}{r}77 \\
89 \\
79 \\
90 \\
94 \\
140 \\
110 \\
78 \\
112 \\
90 \\
100 \\
121 \\
138 \\
143\end{array}$ & $\begin{array}{r}110 \\
78 \\
90 \\
100 \\
117 \\
147 \\
105 \\
100 \\
125 \\
90 \\
125 \\
110 \\
90 \\
107\end{array}$ & $\begin{array}{l}0.35 \\
0.31 \\
0.30 \\
0.28 \\
0.26 \\
0.24 \\
0.28 \\
0.29 \\
0.28 \\
0.29 \\
0.33 \\
0.24 \\
0.24 \\
0.25\end{array}$ & $\begin{array}{l}3500 \\
2760 \\
2350 \\
2875 \\
3420 \\
5340 \\
3450 \\
2670 \\
4610 \\
2900 \\
4820 \\
3365 \\
3625 \\
4380\end{array}$ & $\begin{array}{r}6.8 \\
8.0 \\
7.8 \\
8.4 \\
= \\
10.5 \\
4.5 \\
6.1 \\
= \\
\overline{7.9} \\
12.8 \\
11.3\end{array}$ & $\begin{array}{l}85 \cdot 0 \\
89 \cdot 3 \\
98 \cdot 9 \\
93 \cdot 4 \\
= \\
96 \cdot 0 \\
57 \cdot 7 \\
54 \cdot 5 \\
= \\
6 \overline{5} \cdot 3 \\
92 \cdot 7 \\
77 \cdot 9\end{array}$ & $\begin{array}{c}243 \cdot 0 \\
288 \cdot 5 \\
329 \cdot 5 \\
334 \cdot 0 \\
\overline{-} \\
343 \cdot 0 \\
199 \cdot 0 \\
194 \cdot 8 \\
\overline{-} \\
272 \cdot 0 \\
386 \cdot 5 \\
312 \cdot 0\end{array}$ \\
\hline
\end{tabular}

ejection pressure, ejection time, and heart rate. Statistical comparison is by Student's " $t$ " test.

The following procedure was used: control measurements were made and then the heart rate was increased by atrial pacing starting approximately 5 beats/min. above the control heart rate and increasing with increments of 5-10 beats/min. until the patient first experienced premonitory sensations of angina, a rate of 160 beats/min. was reached, or atrial capture became intermittent. Each rate was maintained for 60-90 sec., pressures being measured at $45 \mathrm{sec}$. Cardiac output was measured after $60 \mathrm{sec}$., at rates of $110,130,150$ beats/ min., and also when angina occurred. During previous studies it became evident that angina occurred within $45 \mathrm{sec}$. of a given rate if this was critical (Sowton et al., 1967). The pacing procedure was repeated once with a 10-minute interval between the pacing runs. Anginal pain was rapidly relieved by a reduction in pacing rate at any time.

Ten minutes after the second pacing run the patients performed exercise in a supine position, on a stationary bicycle ergometer (Elema Schönander) attached to the end of the catheter table. Resting pressures and cardiac output were recorded and then exercise started at a work load of $150 \mathrm{kp} . \mathrm{m} . / \mathrm{min}$., increasing by increments of $150 \mathrm{kp} . \mathrm{m}$./min. at $1 \frac{1}{2}$-minute intervals until angina was first noticed by the patient. Pressures and cardiac output were again recorded at this time.

\section{Results}

Angina pectoris was induced by both atrial pacing and exercise in 14 of the 16 patients studied. Adequate haemodynamic data were obtained in all 16 patients studied, but only the 14 experiencing angina pectoris with both techniques are included in the analysis. No complications were observed in any patient as a result of the test.

The data for the individual patients are shown in Table I and the group means in Table II. The exercise work loads required to produce pain are shown in Table III and the haemodynamic changes produced by exercise in Table IV.

TABLE II

MEAN VALUES AT ONSET OF PAIN INDUCED BY PACING AND EXERCISE FOR 14 PATIENTS

\begin{tabular}{l|c|c}
\hline & Pacing & Exercise \\
\hline Heart rate (beats/min.) & 124 & 105 \\
Mean arterial pressure (mm. Hg) & 102 & 107 \\
Systolic ejection time (sec.) & 0.24 & 0.30 \\
Tension-time index & 3438 & 3579 \\
Cardiac output (1./min.) & 6.9 & 8.4 \\
Stroke volume (ml.) & 54.2 & $81 \cdot 1$ \\
Systolic ejection rate (ml./sec.) & 229.6 & $290 \cdot 2$ \\
\hline
\end{tabular}

TABLE III

NUMBER OF PATIENTS AND CORRESPONDING DURING EXERCISE

\begin{tabular}{c|c}
\hline No. of patients & $\begin{array}{c}\text { Work load (kp.m./min.) } \\
\text { at onset of pain }\end{array}$ \\
\hline 8 & 150 \\
2 & 300 \\
2 & 450 \\
2 & 600 \\
\hline
\end{tabular}

TABLE IV

MEAN VALUES FOR 14 PATIENTS AT CONTROI LEVELS AND AT PAIN PRODUCED BY EXERCISE

\begin{tabular}{l|c|c}
\hline & Control & Pain \\
\hline Heart rate (beats/min.) & 78 & 105 \\
Cardiac output (1./min.) & $7 \cdot 0$ & $8 \cdot 4$ \\
Stroke volume (ml.) & $87 \cdot 5$ & $81 \cdot 1$ \\
Mean arterial pressure (mm. Hg) & 97 & 107 \\
Tension-time index & 2681 & 3550 \\
Systolic ejection time (sec.) & $0 \cdot 30$ & $0 \cdot 30$ \\
Systolic ejection rate (ml./sec.) & $291 \cdot 6$ & $290 \cdot 2$ \\
\hline
\end{tabular}


The heart rate at the point of pain produced by pacing varied between 99 and 140, with a mean of 124 beats/min. At the onset of pain produced by exercise, however, the rate varied between 77 and 145 , with a mean of 104 beats/min., which was a significant difference $(0.01>p>0.001)$. Mean systemic pressure was not significantly different $(0.9>p>0.8)$ at the point of pain induced either by atrial pacing or exercise. It varied from 78 to $130 \mathrm{~mm}$. $\mathrm{Hg}$ (mean 102) with pacing, and from 78 to $147 \mathrm{~mm}$. $\mathrm{Hg}$ (mean 106) with exercise.

Systolic ejection time at pain during pacing ranged from 0.21 to $0.26 \mathrm{sec}$., with a mean of 0.24 . With exercise it ranged from 0.24 to 0.35 sec., with a mean of $0.30 \mathrm{sec}$. This was a significant difference $(\mathrm{p}<0.001)$.

Tension-time index showed considerable variation, but on repeated pacing runs was within 5 per cent of the original value at the onset of pain in any individual patient. It ranged from 2590 to 4900 , with a mean of 3222 , during pacing, and from 2390 to 5340 , with a mean of 3550 , during exercise. This difference was not statistically significant $(0.50>p>$ 0.40 ). The tension-time index data in a typical patient are shown graphically in the Figure.

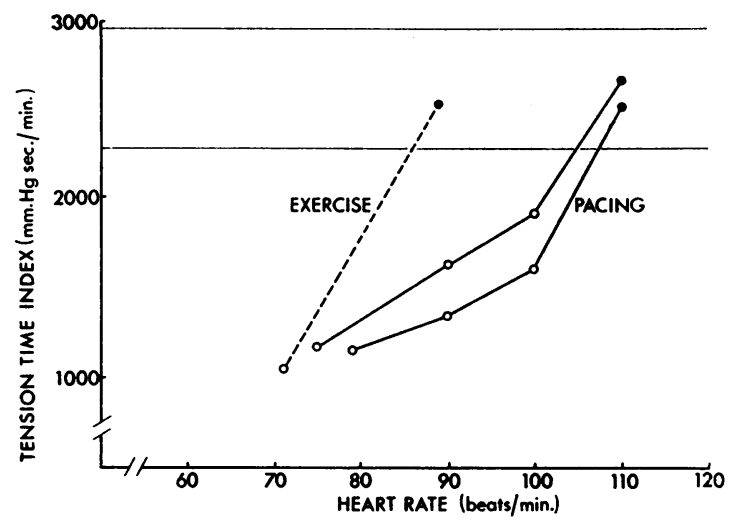

Fig.-Two consecutive pacing runs are represented by the continuous lines and exercise by the broken line. Filled symbols indicate the presence of cardiac pain.

Mean cardiac output was $6.91 . / \mathrm{min}$. during pain (range 3.7 to $12.7 \mathrm{l} . / \mathrm{min}$.) and $8.41 . / \mathrm{min}$. during exercise (range 4.5 to $12.81 . / \mathrm{min}$.). The difference between these means was not statistically significant (p $0.2>p>0.1$ ), though all but one patient had a higher output with exercise. Mean stroke volume was significantly higher on exercise $(0.05>p>0.02)$. The value during pacing was $54.2 \mathrm{ml}$. (range 32.9 to 97.7 ) and $81.1 \mathrm{ml}$. on exercise (range 54.5 to 98.9). Mean systolic ejection rate was faster on exercise compared with pacing though this difference was also not statistically significant $(0 \cdot 1>p>$ 0.05 ). The values were $234.3 \mathrm{ml}$./sec. pacing (range 132 to 376 ) and $290.2 \mathrm{ml} . / \mathrm{sec}$. exercising (range 195 to 386$)$.

\section{Discussion}

The concept that relative myocardial ischaemia precipitates angina pectoris was postulated over 150 years ago, and later workers expounded the theory (Klemperer, 1960), and summarized and added to the evidence (Gorlin, 1965) so that it is now generally accepted. Pain probably begins to occur when myocardial oxygen consumption exceeds its supply. Tension-time index has been shown to be an approximate estimate of myocardial oxygen consumption (Sarnoff et al., 1958), and in this study we have shown that the tension-time index is not significantly different at the point of anginal pain in patients with ischaemic heart disease whether produced by atrial pacing or by exercise.

We were not able to assess changes in left ventricular volume in these patients, but it has been shown (Holmgren and Ovenfors, 1960) that the total heart volume remains unchanged at rest and during increasing supine exercise. During atrial pacing there is a tendency for the heart to become smaller (Glick et al., 1964), and our results may be influenced by this factor which would tend to result in a lower myocardial oxygen consumption at the same tension-time index. This consideration applies to all studies involving atrial pacing and emphasizes that the tension-time index is merely an index which can be conveniently measured and from which broad conclusions may be drawn. Despite the effects of possible alterations in ventricular volume, our present results showed no statistically significant difference between tension-time index during pain induced by the two methods. This finding is compatible with the theory that there is a threshold for anginal pain, which is reached when myocardial oxygen demands just exceed maximal coronary arterial supply.

There was no significant difference between the mean cardiac output at pain during exercise and on pacing. The output was higher on exercise in 12 of the 14 patients-but the rise $(22 \%)$ was relatively small and the increase in output from rest to exercise $(20 \%)$ was also small. This probably indicates poor myocardial function in this group of patients, a finding confirmed by the low exercise levels at which anginal pain was produced (Table III).

Systolic ejection rate was faster on exercise in all but one patient, though this increase was just short 
of statistical significance. The trend probably reflects increased catecholamine drive on exercise.

Since blood pressure did not change and the heart rate was lower during exercise, the prolongation of ejection due to the larger stroke volume accounts for the equality of the tension-time index during the two tests.

Atrial pacing seems to offer good physiological correlation compared with exercise and has some advantages, the most important of which is that a relatively steady state can be obtained for short periods of time enabling accurate and repeatable measurements to be made, in contrast to exercise where conditions are constantly changing and difficult to assess. Anginal pain seems also to occur with exercise before the point where any steady state can be achieved.

For any individual patient anginal pain is experienced at approximately the same tension-time index whether the pain is produced by atrial pacing or by supine exercise. This suggests that conclusions based upon atrial pacing are clinically relevant for assessment of patients with angina pectoris.

\section{SUMMARY}

Angina pectoris has been produced by a new method in a group of patients with ischaemic heart disease. The heart rate was increased by atrial pacing and various haemodynamic parameters measured. It has previously been found that pain occurred repeatedly at the same tension-time level on each pacing run. The group of patients described also performed exercise on a bicycle ergometer until pain occurred. The tension-time index level at the point of pain was the same whether produced by atrial pacing or by exercise. It is concluded that there is a tension-time threshold level above which angina will occur however this level is reached, provided that parameters which alter myocardial oxygen consumption and yet are not reflected in the tension-time index, such as ventricular volume, do not change. Atrial pacing can be used to provide an objective assessment of patients with angina pectoris, particularly those being considered for remedial surgery. It can also be used to follow the results of such procedures.

We wish to thank our colleagues at the National Heart Hospital and elsewhere who kindly referred patients for investigation, and to acknowledge with gratitude the technical help of Miss Janet Woods.

\section{REFERENCES}

Burkart, F., Barold, S., and Sowton, E. (1967). Hemodynamic effects of repeated exercise. Amer. F. Cardiol., 20, 509.

Friesinger, G. C., Conti, C. R., and Pitt, B. (1967). Observations on left ventricular pressure during angina pectoris. (Abstract.) Circulation, 36, Suppl. 2, p. 115.

Glick, C., Williams, J. F., Harrison, D. C., Morrow, A. G., and Braunwald, E. (1964). Effect of heart rate on cardiac dimensions in unanaesthetized man. Studies during electrical pacing. Physiologist, 7, 143.

Gorlin, R. (1965). Pathophysiology of cardiac pain. Circulation, 32, 138.

Holmgren, A., and Ovenfors, C. O. (1960). Heart volume at rest and during muscular work in the supine and in the sitting position. Acta med. scand., 167, 267.

Klemperer, P. (1960). The history of coronary sclerosis. Amer. F. Cardiol., 5, 94.

Lau, S. H., Haft, J. I., Cohen, S. I., Helfant, R. H., Young, M. W., and Damato, A. N. (1967a). Controlled heart rate as a determinant of $S-T$ changes in myocardial ischemia: A standardized stress test. (Abstract.) Circulation, 36, Suppl. 2, p. 169.

,,,--- Kinney, M. J., Helfant, R. H., and Damato, A. N. (1967b). Controlled heart rates in evaluation of angina pectoris (A.P.). (Abstract.) Clin. Res., 15, 212.

Sarnoff, S. J., Braunwald, E., Welch, G. H., Jr., Case, R. B., Stainsby, W. N., and Macruz, R. (1958). Hemodynamic determinants of oxygen consumption of the heart with special reference to the tension-time index. Amer. F. Physiol., 192, 148.

Sowton, G. E., Balcon, R., Cross, D., and Frick, M. H. (1967). Measurement of the angina threshold using atrial pacing. A new technique for the study of angina pectoris. Cardiovasc. Res., 1, 301. 